\title{
Lessons From the World Trade Center Disaster
}

\section{Airway Disease Presenting as Restrictive Dysfunction}

\author{
Kenneth I. Berger, MD, FCCP; Joan Reibman, MD; Beno W. Oppenheimer, MD; \\ Ioannis Vlahos, MD; Denise Harrison, MD; and Roberta M. Goldring, MD
}

\begin{abstract}
Background: The present study (1) characterizes a physiologic phenotype of restrictive dysfunction due to airway injury and (2) compares this phenotype to the phenotype of interstitial lung disease (ILD).

Methods: This is a retrospective study of 54 persistently symptomatic subjects following World Trade Center (WTC) dust exposure. Inclusion criteria were reduced vital capacity (VC), $\mathbf{F E V} \mathbf{I}_{\mathbf{l}} \mathbf{V C}>\mathbf{7 7 \%}$, and normal chest roentgenogram. Measurements included spirometry, plethysmography, diffusing capacity of lung for carbon monoxide (DLCO), impulse oscillometry (IOS), inspiratory/expiratory CT scan, and lung compliance $(\mathbf{n}=16)$.

Results: VC was reduced (46\% to $83 \%$ predicted) because of the reduction of expiratory reserve volume $(43 \% \pm 26 \%$ predicted $)$ with preservation of inspiratory capacity $(\mathrm{IC})(85 \% \pm 16 \%$ predicted $)$. Total lung capacity (TLC) was reduced, confirming restriction $(73 \% \pm 8 \%$ predicted); however, elevated residual volume to TLC ratio $(0.35 \pm 0.08)$ suggested air trapping (AT). DLCo was reduced $(78 \% \pm 15 \%$ predicted) with elevated DLco/alveolar volume $(5.3 \pm 0.8[\mathrm{~mL} / \mathrm{mm} \mathrm{Hg} / \mathrm{min}] / \mathrm{L})$. IOS demonstrated abnormalities in resistance and/or reactance in 50 of 54 subjects. CT scan demonstrated bronchial wall thickening and/or AT in 40 of 54 subjects; parenchymal disease was not evident in any subject. Specific compliance at functional residual capacity (FRC) $\left(0.07 \pm 0.02\left[\mathrm{~L} / \mathrm{cm} \mathrm{H}_{2} \mathrm{O}\right] / \mathrm{L}\right)$ and recoil pressure $(\mathrm{Pel})$ at $\mathrm{TLC}\left(27 \pm 7 \mathrm{~cm} \mathrm{H}_{2} \mathrm{O}\right)$ were normal. In contrast to patients with ILD, lung expansion was not limited, since IC, Pel, and inspiratory muscle pressure were normal. Reduced TLC was attributable to reduced FRC, compatible with airway closure in the tidal range.

Conclusions: This study describes a distinct physiologic phenotype of restriction due to airway dysfunction. This pattern was observed following WTC dust exposure, has been reported in other clinical settings (eg, asthma), and should be incorporated into the definition of restrictive dysfunction.
\end{abstract}

CHEST 2013; 144(1):249-257

Abbreviations: AT = air trapping; $\mathrm{AX}=$ reactance area; $\mathrm{Csp}=$ specific lung compliance; $\mathrm{Cst}, 1=$ static lung compliance; $\mathrm{DLCO}=$ diffusion capacity of the lung for carbon monoxide; $\mathrm{ERV}=$ expiratory reserve volume; $\mathrm{FRC}=$ functional residual capacity; Fres = resonant frequency; IC = inspiratory capacity; ILD = interstitial lung disease; IOS = impulse oscillometry; $\mathrm{LLN}=$ lower limit of normal; $\mathrm{Pel}=$ elastic recoil pressure of the lung; $\mathrm{R}_{5}=$ resistance at an oscillation frequency of $5 \mathrm{~Hz} ; \mathrm{R}_{20}=$ resistance at an oscillation frequency of $20 \mathrm{~Hz} ; \mathrm{R}_{5-20}=$ resistance at $5 \mathrm{~Hz}$ minus resistance at $20 \mathrm{~Hz}$; $\mathrm{RV}=$ residual volume; $\mathrm{TLC}=$ total lung capacity; $\mathrm{ULN}=$ upper limit of normal; $\mathrm{VA}=$ alveolar volume; $\mathrm{VC}=$ vital capacity; WTC $=$ World Trade Center

B aldwin et $a^{1}$ defined pulmonary function abnormalities as obstructive or restrictive patterns. The obstructive pattern is a hallmark of airway disease; restrictive ventilatory insufficiency was defined as "restriction in pulmonary expansion and contraction from one or another dynamic or structural causes other than obstruction of airways." However, true restriction, confirmed by reduced total lung capacity
(TLC) and normal airflow, has been reported in case reports and small case series of subjects with asthma. ${ }^{2-5}$ These subjects are not readily classifiable into the classic obstructive or restrictive patterns.

This inconsistency has been highlighted in symptomatic subjects following World Trade Center (WTC) dust exposure. The predominant physiologic abnormality in these subjects is reduced vital capacity $(\mathrm{VC})$ 
with preservation of $\mathrm{FEV}_{1} / \mathrm{VC}$. 6 -10 Although TLC has not been consistently reported, chest radiographs have generally been normal, and parenchymal disease is not evident in the majority of subjects. Airway disease was demonstrated by bronchial hyperreactivity or presence of bronchial wall thickening and/or air trapping (AT) on CT scan..$^{7,10-13}$

This population of subjects exposed to WTC dust with unexplained reduction in $\mathrm{VC}$ provided the opportunity to assess airway and parenchymal mechanics in addition to spirometry and plethysmography. The present study (1) characterizes a physiologic phenotype of restrictive dysfunction due to airway injury and (2) contrasts the restrictive dysfunction from airway disease to the physiologic phenotype of patients with interstitial lung disease (ILD).

\section{Materials AND Methods}

This study retrospectively analyzed data from 54 subjects with persistent respiratory symptoms and unexplained reduction in VC. Inclusion criteria were as follows: (1) exposure to WTC dust, (2) reduction in $\mathrm{VC}$ below the lower limit of normal (LLN) on initial screening spirometry, ${ }^{14}(3) \mathrm{FEV}_{1} / \mathrm{VC} \geq 77 \%$ (mean $\pm \mathrm{SD}$, $82 \% \pm 5 \%$ ) (this value exceeds the LLN of commonly used predicted equations and ensures that subjects with mild large airway disease were excluded ${ }^{15}$ ), and (4) absence of parenchymal, pleural, or chest wall abnormality on chest radiography. Patients were referred from the Bellevue Hospital WTC Environmental Health Center and the New York University WTC Clinical Center of Excellence. Initial physiologic evaluation occurred between March 2002 and February 2009; reduction of VC prompted referral for oscillometry, plethysmography, and CT scan. Patients completing these studies using stringent criteria (described later) were included. WTC dust exposure was determined by patient interview, since environmental measurements do not provide quantitative data for individual exposures. ${ }^{16}$ Subjects were classified as exposure to

Manuscript received June 14, 2012; revision accepted December 17, 2012.

Affiliations: From the André Cournand Pulmonary Physiology Laboratory (Drs Berger, Oppenheimer, and Goldring); the World Trade Center Environmental Health Center (Drs Berger, Reibman, and Goldring), Bellevue Hospital; the Division of Pulmonary, Critical Care and Sleep Medicine (Drs Berger, Reibman, Oppenheimer, Harrison, and Goldring), New York University School of Medicine; New York University World Trade Center Health Program Clinical Center of Excellence (Dr Harrison), New York, NY; and the Department of Radiology (Dr Vlahos), St. George's Healthcare National Health Service Trust, London, England.

Funding/Support: This work was supported by the Centers for Disease Control and Prevention [Grants 200-2011-39413, 200-2011-39391, and 200-2011-39397], the National Institute for Occupational Safety and Health [Grant 5E11OH009630], and the American Red Cross Liberty Disaster Relief Fund, City of New York.

Correspondence to: Kenneth I. Berger, MD, FCCP, New York University School of Medicine, 240 E 38 St, Room M15, New York, NY 10016; e-mail: kenneth.berger@nyumc.org

(C) 2013 American College of Chest Physicians. Reproduction of this article is prohibited without written permission from the American College of Chest Physicians. See online for more details. DOI: 10.1378/chest.12-1411 dust cloud caused by a building collapse and additionally as rescue/recovery personnel, cleanup workers, and workers or residents in the surrounding community. ${ }^{6}$ Self-reported history of smoking and prior lung disease were recorded.

Spirometry, lung volumes, and diffusing capacity of the lung for carbon monoxide (DLCO) were measured (Vmax; CareFusion), and the resulting values were related to published normative data. ${ }^{14,17-21}$ Criteria to ensure maximal effort for measurement of $\mathrm{VC}$ included the following: (1) exhalation time $\geq 6 \mathrm{~s},(2)$ plateau of exhaled volume vs time tracing, and (3) three or more trials with reproducible data. Inspiratory capacity (IC) and expiratory reserve volume (ERV) were determined from tracings with stable end-expiratory lung volume and tidal volume $<750 \mathrm{~mL}$. Functional residual capacity (FRC) was measured by plethysmography. Spirometry was repeated 15 to $20 \mathrm{~min}$ following nebulized albuterol.

\section{Impulse Oscillometry}

Impulse oscillometry (IOS) was measured with the Jaeger Impulse Oscillation System (Jaeger USA) during tidal breathing with support of the cheeks. ${ }^{22}$ Resistance and reactance were calculated from airflow and pressure oscillations between frequencies of 5 to $35 \mathrm{~Hz}$. Parameters included the following: (1) resistance at oscillation frequencies of $20 \mathrm{~Hz}\left(\mathrm{R}_{20}\right)$ and $5 \mathrm{~Hz}\left(\mathrm{R}_{5}\right)$, (2) frequency dependence of resistance calculated as change in resistance between 5 and $20 \mathrm{~Hz}\left(\mathrm{R}_{5-20}\right)$, (3) resonant frequency (Fres), and (4) reactance area $(\mathrm{AX})$. Trials with stable tidal and end-expiratory volume were analyzed. Since IOS analyzes 150 impulses over a 30-s measurement, coherence $>0.7$ at $5 \mathrm{~Hz}$ and $>0.85$ at $10 \mathrm{~Hz}$ were required. ${ }^{23,24}$ Reproducibility between trials (variability $<10 \%$ ) was required. Conservative upper limits of normal (ULN) were selected that approximate $150 \%$ of mean data in normal subjects. ${ }^{9,15,25-28}$ Data obtained in our laboratory in 80 asymptomatic nonsmoking subjects with normal spirometry and without lung disease fell within these limits.

\section{Lung Compliance}

All subjects were referred for compliance testing to clinically evaluate reduced TLC in symptomatic individuals not explained by chest radiographs. Data were obtained $(n=16)$ using an esophageal catheter (AKRAD Laboratories; CooperSurgical Inc) positioned in the distal esophagus. ${ }^{29,30}$ Static lung compliance (Cst, 1 ) was measured after two IC maneuvers by periodically occluding the airway during a passive exhalation from TLC to FRC. Specific lung compliance (Csp) was calculated by dividing Cst, 1 by FRC. Maximal elastic recoil pressure of the lung (Pel) was measured at TLC; the coefficient of retraction was calculated by dividing Pel by TLC.

\section{CT Scan}

All subjects underwent high-resolution $(1 \mathrm{~mm})$ inspiratory and end-expiratory CT scan from the thoracic inlet to the hemidiaphragms using multidetector scanners. Images were analyzed by a radiologist blinded to clinical and physiologic data. Qualitative assessment was performed since studies were obtained as part of routine clinical management, in which standardized expiration is difficult. Bronchial wall thickening was graded as absent, mild, moderate, or severe. AT was defined by increased heterogeneity of aeration on end-expiratory as compared with inspiratory images. AT was rated as absent, minimal/physiologic (1-2 lobules), mild, moderate, or severe based on number and size of regions involved and severity of expiratory change. Since the severity grade did not relate to physiologic variables, only presence or absence is reported. 


\section{Statistical Analysis}

Data were summarized as means $\pm \mathrm{SD}$ or SE. Differences between groups were assessed using analysis of variance or Mann-Whitney $U$ test. Statistical significance was determined as $P<.05$. Analyses were performed using SPSS for Windows v13.0 (IBM). This study was approved by the New York University Medical School and Bellevue Hospital Institutional Review Board (protocol \#08-516).

\section{RESULTS}

Table 1 illustrates clinical characteristics of the patients. Mean age was $47 \pm 10$ years. Potential causes for airway dysfunction included current/prior cigarette smoking in $39 \%$ of subjects, history of asthma in $15 \%$, and obesity in $49 \%$. Approximately one-half the cohort reported dust cloud exposure. Predominant symptoms were cough and exertional dyspnea. By design, $\mathrm{FEV}_{1} / \mathrm{VC}$ was $\geq 77 \%$ in all subjects. The expiratory flow rate measured at $50 \%$ of $\mathrm{VC}$ was normal (expressed relative to $\mathrm{VC}$ ) in all subjects.

Figure 1 illustrates the lung volumes $( \pm \mathrm{SD})$. All subjects demonstrated reduced VC (range 46\%-83\% predicted). Reduced VC was predominantly due to reduced ERV $(43 \% \pm 26 \%$ predicted) rather than reduced IC ( $85 \% \pm 16 \%$ predicted). TLC was below the LLN in all subjects, confirming restriction. ${ }^{21}$ Mean values for FRC and TLC were $70.0 \% \pm 14 \%$ and $73 \% \pm 8 \%$ predicted, respectively. ${ }^{21}$ Reduced FRC and TLC were not related to BMI $\left(r^{2}<0.04\right)$. Mean value for residual volume $(\mathrm{RV}) / \mathrm{TLC}$ was $0.35 \pm 0.08$, suggesting AT despite low TLC.

Table 1-Clinical Characteristics

\begin{tabular}{lc}
\hline \hline Characteristics & Data \\
\hline Age, mean \pm SD, y & $47 \pm 10$ \\
Male sex & 52 \\
Current smokers & 17 \\
Past smokers & 22 \\
Associated disease & \\
Asthma history & 15 \\
Obesity & \\
$\quad$ BMI 30-35 kg/m² & 33 \\
$\quad$ BMI > 35 kg/m² & 15 \\
Exposure historya & \\
Dust cloud & 48 \\
Rescue/recovery worker & 7 \\
Cleanup worker & 11 \\
Work near WTC & 31 \\
Residence near WTC & 2 \\
Unspecified & 4 \\
Symptoms & \\
Cough & 76 \\
Dyspnea & 74 \\
Wheeze & 43 \\
Chest tightness & 37 \\
\hline
\end{tabular}

Data are presented as \% unless otherwise noted. WTC $=$ World Trade Center.

a Sum is $>100 \%$ because categories are not mutually exclusive.

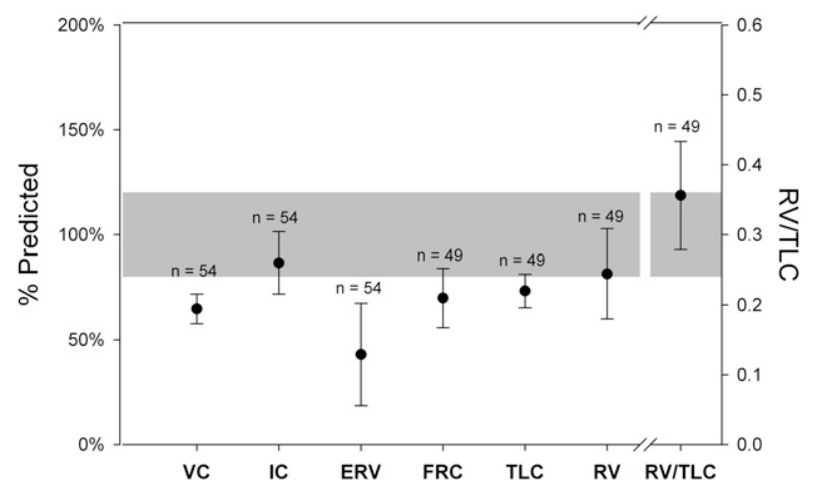

Figure 1. Mean values for measured lung volumes are illustrated $( \pm$ SD). The shaded area represents normal range. Valid data for FRC, TLC, and RV were obtainable in 49 of 54 subjects. $\mathrm{ERV}=$ expiratory reserve volume; $\mathrm{FRC}=$ functional residual capacity; $\mathrm{IC}=$ inspiratory capacity; $\mathrm{RV}=$ residual volume; $\mathrm{TLC}=$ total lung capacity; $\mathrm{VC}=$ vital capacity.

Data for DLCO were available in 46 of 54 subjects. The mean value $( \pm \mathrm{SD})$ was minimally reduced $(78 \% \pm$ $15 \%$ predicted), and the DLCo to alveolar volume (VA) ratio was elevated $(5.3 \pm 0.8[\mathrm{~mL} / \mathrm{mm} \mathrm{Hg} / \mathrm{min}] / \mathrm{L})$. The VA measured by gas dilution was related to the plethysmographic TLC. VA/TLC averaged $82 \% \pm 9 \%$; values $<85 \%$ were detected in $56 \%$ of subjects, indicating nonuniformity of gas distribution.

\section{Impulse Oscillometry}

Overall, 50 of 54 subjects demonstrated abnormalities in either respiratory resistance or reactance. Only 12 subjects demonstrated elevated resistance by plethysmography. Figure 2 illustrates baseline oscillometry data and response to bronchodilator. Mean values were above the ULN $\left(\mathrm{R}_{20}, 3.96 \pm 0.22 \mathrm{~cm} \mathrm{H}_{2} \mathrm{O} / \mathrm{L} / \mathrm{s}\right.$; $\mathrm{R}_{5-20}, 1.45 \pm 0.10 \mathrm{~cm} \mathrm{H} \mathrm{H}_{2} \mathrm{O} / \mathrm{L} / \mathrm{s} ;$ Fres, $18.1 \pm 0.7 \mathrm{~Hz} ; \mathrm{AX}$, $\left.13.39 \pm 1.54 \mathrm{~cm} \mathrm{H}_{2} \mathrm{O} / \mathrm{L}\right)$. Although values decreased following bronchodilator administration, the magnitude of change was relatively small and persistent abnormality was noted in the majority $\left(\mathrm{R}_{20}, 3.49 \pm\right.$ $0.17 \mathrm{~cm} \mathrm{H}_{2} \mathrm{O} / \mathrm{L} / \mathrm{s} ; \mathrm{R}_{5-20}, 1.25 \pm 0.11 \mathrm{~cm} \mathrm{H}_{2} \mathrm{O} / \mathrm{L} / \mathrm{s} ;$ Fres, $15.5 \pm 0.6 \mathrm{~Hz} ; \mathrm{AX}, 8.87 \pm 1.25 \mathrm{~cm} \mathrm{H}_{2} \mathrm{O} / \mathrm{L} ; P<.05$ vs baseline). Postbronchodilator spirometry revealed no change in $\mathrm{VC}$ or $\mathrm{FEV}_{1}$.

Table 2 illustrates oscillometry data after categorizing subjects based on BMI. For nonobese subjects $\left(\mathrm{BMI}<30 \mathrm{~kg} / \mathrm{m}^{2}\right)$, mean values for all variables were above the ULN, suggesting airway dysfunction despite normal $\mathrm{FEV}_{1} / \mathrm{NC}$. The obese and morbidly obese subgroups demonstrated increasing abnormality. Data were not different $(P>.05)$ in subjects with history of smoking or asthma $(n=24)$ vs the remaining subjects.

\section{CT Scan}

Parenchymal disease was not evident in any subject. Inspiratory images revealed bronchial wall thickening 


\section{RESISTANCE}
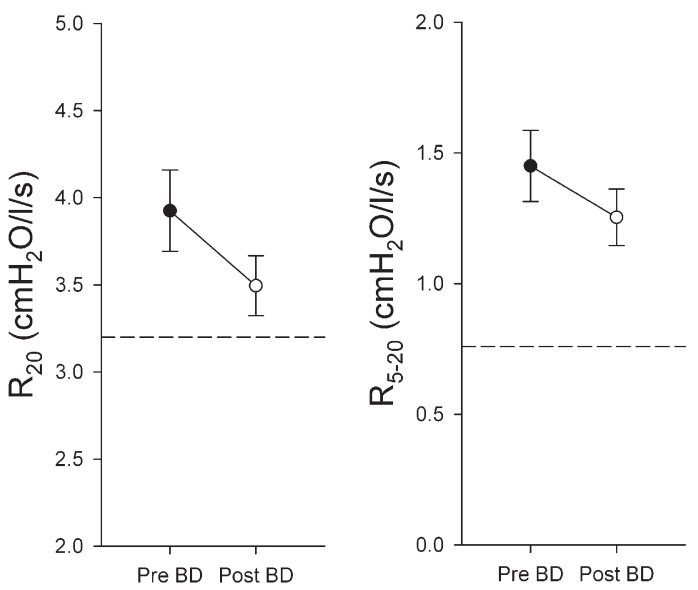

\section{REACTANCE}
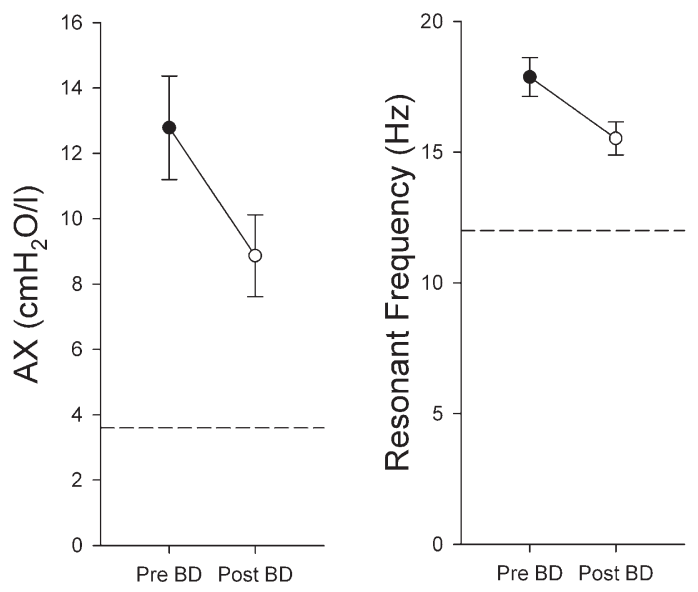

FigurE 2. IOS parameters $\left(\mathrm{R}_{20}, \mathrm{R}_{5-20}\right.$, resonant frequency, and $\mathrm{AX})$ are illustrated. Mean values $\pm \mathrm{SE}$ are plotted before $(\mathbf{)})$ and after $(\bigcirc)$ bronchodilator administration. The dashed line represents the published upper limit of normal for each parameter. Data are shown for the 49 of 54 subjects with valid postbronchodilator data. $\mathrm{AX}=$ reactance area $\mathrm{BD}=$ bronchodilator; $\mathrm{IOS}=$ impulse oscillometry; $\mathrm{R}_{20}=$ resistance at an oscillation frequency of $20 \mathrm{~Hz}$; $\mathrm{R}_{5-20}=$ resistance at $5 \mathrm{~Hz}$ minus resistance at $20 \mathrm{~Hz}$.

in 30 subjects and expiratory images revealed AT in 29 subjects. Overall, 40 of 54 subjects (74\%) demonstrated either bronchial wall thickening and/or AT, indicating airway disease. Lung volume and oscil- lometry data were similar in subjects with abnormal vs normal CT scan $(P>.05)$.

\section{Lung Compliance}

Compliance measurements were obtained in 16 of 54 subjects who consented (Table 3 ). These subjects did not differ from the remaining subjects with respect to age, sex, height, weight, lung volumes, airflow, diffusion, airway resistance, or IOS measurements. Cst, 1 measured at FRC was at the $\mathrm{LLN}\left(0.14 \pm 0.03 \mathrm{~L} / \mathrm{cm} \mathrm{H}_{2} \mathrm{O}\right)$. However, when data were expressed as Csp to account for reduced FRC, values were at the ULN $(0.07 \pm$ $\left.0.02\left[\mathrm{~L} / \mathrm{cm} \mathrm{H}_{2} \mathrm{O}\right] / \mathrm{L}, \mathrm{ULN}=0.06\left[\mathrm{~L} / \mathrm{cm} \mathrm{H}_{2} \mathrm{O}\right] / \mathrm{L}\right)$. The Pel at TLC $\left(27 \pm 7 \mathrm{~cm} \mathrm{H}_{2} \mathrm{O}\right)$ and the coefficient of retraction $\left(6.6 \pm 2.3 \mathrm{~cm} \mathrm{H}_{2} \mathrm{O} / \mathrm{L}\right)$ were within normal limits. Maximal inspiratory muscle pressure averaged $-72 \pm 25 \mathrm{~cm} \mathrm{H}_{2} \mathrm{O}$; values for percent predicted were similar in male and female subjects.

\section{Comparison With ILD}

Physiologic data were compared with published observations from 52 patients with confirmed ILD. ${ }^{31,32}$ Data were obtained in this laboratory using identical testing procedures as used in the present study.

Figure 3 illustrates a maximal flow-volume curve for a patient in the present study compared with a patient with ILD with similar VC. The maximal flowvolume curves were similar in these subjects. However, the position of the tidal volume curve within the maximal envelope differed, reflecting differing mechanisms for reduced VC: In the WTC dust-exposed subject, the tidal loop was shifted to the right of the flow-volume envelope, indicating isolated reduction in ERV vs reduction in both IC and ERV in the patient with ILD, where the tidal loop remained centrally located. Furthermore, in the WTC dust-exposed patient, the tidal expiratory airflow approached the maximal airflow, suggesting potential for expiratory flow limitation during tidal breathing.

Figure 4 plots DLCO as a function of TLC. The shaded area depicts published observations from patients with ILD over a similar range of TLC. ${ }^{31,32}$ DLCO was

Table 2-Relationship Between IOS Data and BMI

\begin{tabular}{lcccc}
\hline \hline IOS Parameter & Upper Limit of Normal & BMI $<30 \mathrm{~kg} / \mathrm{m}^{2}(\mathrm{n}=28)$ & BMI 30-35 kg/m² $(\mathrm{n}=18)$ & $\mathrm{BMI}>35 \mathrm{~kg} / \mathrm{m}^{2}(\mathrm{n}=8)$ \\
\hline $\mathrm{R}_{5}$ & $3.96 \mathrm{~cm} \mathrm{H}_{2} \mathrm{O} / \mathrm{L} / \mathrm{s}$ & $4.69 \pm 1.73$ & $5.39 \pm 1.29$ & $8.52 \pm 3.34^{\mathrm{a}}$ \\
$\mathrm{R}_{20}$ & $3.20 \mathrm{~cm} \mathrm{H}_{2} \mathrm{O} / \mathrm{L} / \mathrm{s}$ & $3.49 \pm 1.24$ & $3.79 \pm 0.87$ & $6.00 \pm 2.60^{\mathrm{a}}$ \\
$\mathrm{R}_{5-20}$ & $0.76 \mathrm{~cm} \mathrm{H}_{2} \mathrm{O} / \mathrm{L} / \mathrm{s}$ & $1.13 \pm 0.80$ & $1.60 \pm 0.73$ & $2.53 \pm 1.21^{\mathrm{a}}$ \\
$\mathrm{AX}$ & $3.60 \mathrm{~cm} \mathrm{H}_{2} \mathrm{O} / \mathrm{L}$ & $9.06 \pm 7.27$ & $13.85 \pm 10.09$ & $27.49 \pm 14.57^{\mathrm{a}}$ \\
Fres & $12 \mathrm{~Hz}$ & $16.32 \pm 4.39$ & $18.74 \pm 4.82$ & $22.91 \pm 5.28^{\mathrm{a}}$ \\
\hline
\end{tabular}

Data are presented as mean $\pm \mathrm{SD} . \mathrm{AX}=$ reactance area; Fres $=$ resonant frequency; $\mathrm{IOS}=$ impulse oscillometry; $\mathrm{R}_{5}=$ resistance at an oscillation frequency of $5 \mathrm{~Hz} ; \mathrm{R}_{20}=$ resistance at an oscillation frequency of $20 \mathrm{~Hz} ; \mathrm{R}_{5-20}=$ resistance at $5 \mathrm{~Hz}$ minus resistance at $20 \mathrm{~Hz}$.

${ }^{a} P<.01$ for difference as compared with patients with $\mathrm{BMI}<30$ and $\mathrm{BMI} 30-35 \mathrm{~kg} / \mathrm{m}^{2}$. 
Table 3-Lung Compliance $(n=16)$

\begin{tabular}{lc}
\hline \hline Parameter & Mean $\pm \mathrm{SD}$ \\
\hline Cst,l, L/cm $\mathrm{H}_{2} \mathrm{O}$ & $0.14 \pm 0.03$ \\
$\mathrm{Csp},\left[\mathrm{L} / \mathrm{cm} \mathrm{H} \mathrm{H}_{2} \mathrm{O}\right] / \mathrm{L}$ & $0.07 \pm 0.02$ \\
Pel at TLC, cm $\mathrm{H}_{2} \mathrm{O}$ & $27 \pm 7$ \\
Coefficient of retraction, $\mathrm{cm} \mathrm{H} \mathrm{H}_{2} \mathrm{O} / \mathrm{L}$ & $6.6 \pm 2.3$ \\
TLC, \% predicted & $70.3 \pm 8.4$ \\
Max inspiratory pressure, $\mathrm{cm} \mathrm{H}_{2} \mathrm{O}$ & $-72 \pm 25$
\end{tabular}

$\mathrm{Csp}=$ specific lung compliance; Cst, $\mathrm{l}=$ static lung compliance; $\mathrm{Pel}=$ elastic recoil pressure of the lung; TLC $=$ total lung capacity.

consistently higher in patients from the present study compared with subjects with ILD.

Figure 5 illustrates the maximal recoil pressure as a function of TLC. The shaded area depicts published observations obtained in patients with ILD and demonstrates values above the ULN in accord with parenchymal stiffness. ${ }^{31,32}$ In contrast, for subjects in this study, maximal recoil pressure was within normal limits in all but one subject. Similarly, the coefficient of retraction was elevated in subjects with ILD (11.7 \pm 5.7 , mean \pm SD), confirming parenchymal stiffness as compared with borderline high values seen in this study $\left(6.6 \pm 2.3 \mathrm{~cm} \mathrm{H}_{2} \mathrm{O} / \mathrm{L}\right)$.

\section{DISCUSSION}

This study demonstrates a distinct physiologic phenotype that differs from classic obstructive and restrictive patterns. The abnormality resembled a restrictive defect, with reduced VC, FRC, and TLC and preservation of $\mathrm{FEV}_{1} / \mathrm{VC}$, but parenchymal, chest wall, or neuromuscular disease were not present. Plethysmography demonstrated AT, oscillometry demonstrated abnormalities responsive to bronchodilator, and although DLCo was variably reduced, DLCO/VA was normal or elevated in all subjects. Thus, despite reduction of TLC, data were compatible with an obstructive process. High-resolution CT scan confirmed presence of airway disease in the majority of subjects and excluded parenchymal disease in all subjects. This physiologic phenotype has previously been reported in subjects with asthma, ${ }^{2-5,33,34}$ is currently observed following WTC dust exposure, and differs from observations obtained in subjects with restriction due to ILD.

The data suggest that reduced TLC following WTC dust exposure resulted from functional abnormalities in the distal lung. In contrast to patients with ILD, lung expansion was not limited, since IC, Pel, and inspiratory muscle pressure were normal. Thus, reduction in TLC was attributable to reduced FRC and therefore is compatible with airway closure in the tidal range. IOS obtained during tidal breathing documented abnormalities in resistance and in parameters indicative of nonuniformity of airflow distribution in distal lung $\left(\mathrm{R}_{5-20}\right.$ and $\left.\mathrm{AX}\right){ }^{25,35,36} \mathrm{R}_{5-20}$ and $\mathrm{AX}$ correlate with frequency dependence of lung compliance, an established test of distal airway function. ${ }^{30,37,38}$

The present study expands on prior publications addressing distal airway disease. Because of large aggregate cross-sectional area, airflow may be normal and distal airways have been labeled the "silent zone" of the lung. ${ }^{39,40}$ Thus, detection of distal airway disease was dependent on detecting heterogeneity of airflow
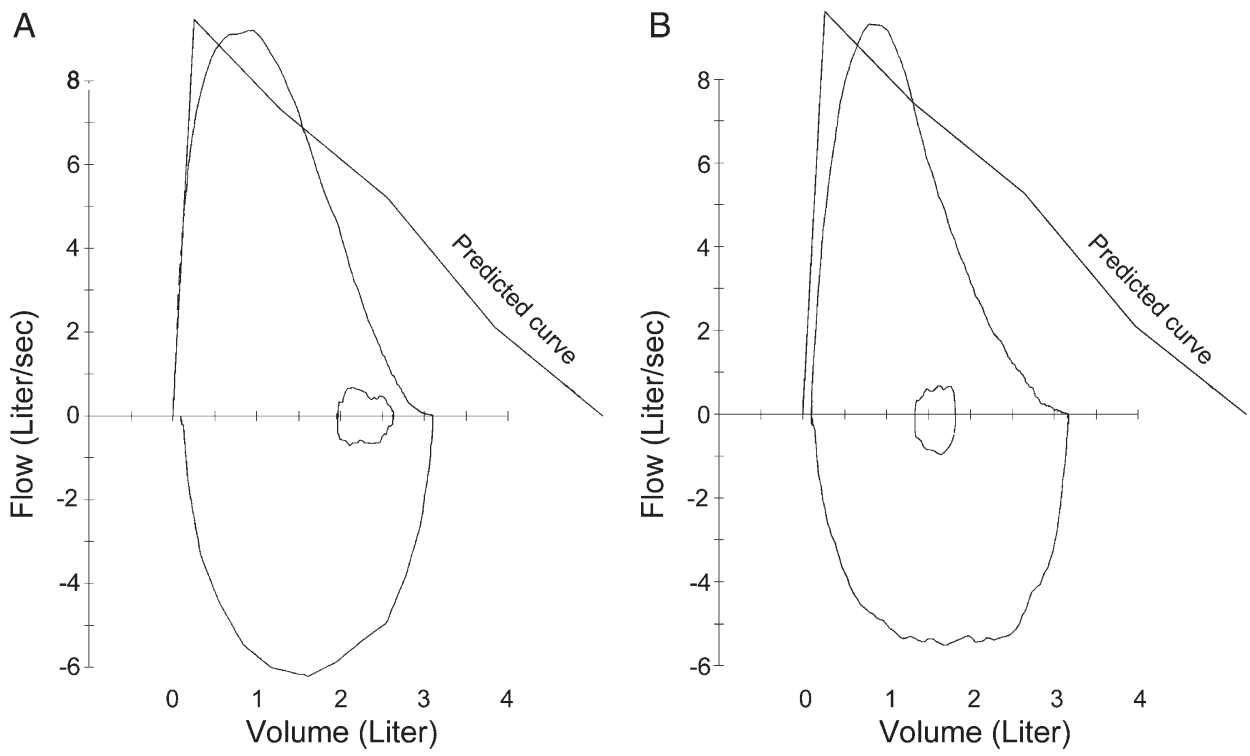

Figure 3. Maximal expiratory flow-volume curves. A, A representative patient in the present study. B, A patient with known interstitial lung disease with similar vital capacity. Tidal loops are superimposed upon the maximal curves for both subjects. 


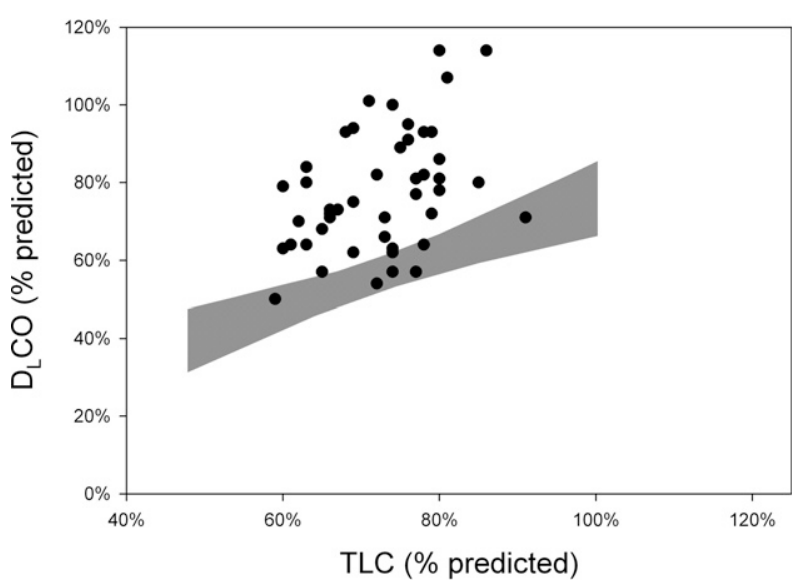

Figure 4 . The measured $\mathrm{D}_{\mathrm{L}} \mathrm{CO}$ is plotted as a function of TLC in each of the subjects. Data are plotted on the background of prior published observations in patients with confirmed interstitial lung disease (shaded area depicts mean $\pm 95 \% \mathrm{CI}$ ). $\mathrm{D}_{\mathrm{L}} \mathrm{CO}=$ diffusion capacity of the lung for carbon monoxide. See Figure 1 legend for expansion of other abbreviation.

distribution rather than increased airway resistance. ${ }^{41,42}$ Stănescu ${ }^{43}$ extended this syndrome to the "nonspecific" pattern of lung dysfunction, wherein $\mathrm{VC}$ is reduced but $\mathrm{FEV}_{1} / \mathrm{NC}$ and TLC remain within normal limits. $\mathrm{RV}$ was increased, indicating AT, and the term "small airway obstructive syndrome" was coined. Recent recommendations for interpreting pulmonary function tests acknowledged this pattern and attributed it to patchy small airway obstruction but also indicated that TLC would be expected to remain within normal limits. ${ }^{44}$ The present article, coupled with prior observations in asthma, ${ }^{2-5,33,34}$ extends these findings by indicating that TLC may be reduced in some individuals with this syndrome who present with true restriction.

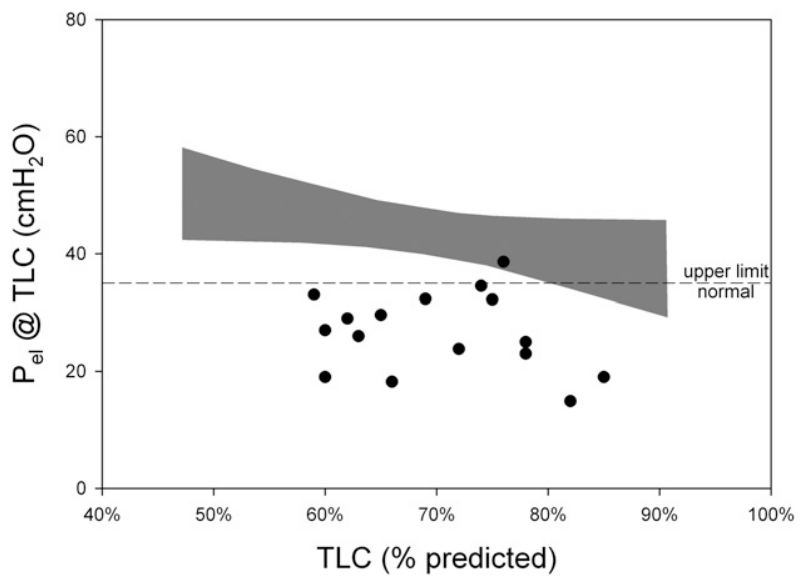

Figure 5. Maximal $\mathrm{P}_{\mathrm{el}}$ is plotted as a function of the measured TLC in each subject. Data are plotted on the background of prior published data obtained in patients with confirmed interstitial lung disease (shaded area depicts mean $\pm 95 \% \mathrm{CI}$ ). $\mathrm{P}_{\mathrm{el}}=$ elastic recoil pressure of the lung. See Figure 1 legend for expansion of other abbreviation.
The predominant spirometric abnormality following WTC dust exposure was reduced VC with normal $\mathrm{FEV}_{1} / \mathrm{NC}^{6-10}$ Studies postulated primary airway rather than parenchymal disease based on normal chest radiographs and either bronchial hyperreactivity and/or airway wall thickening and AT on CT scan examination. $7,10,12,13,29$ The fall in VC in firefighters from before to after September 11, 2001, correlated with degree of AT assessed by plethysmography, ${ }^{12}$ and reduced VC and TLC was associated with AT on CT scan in other first responders. ${ }^{11}$ The present study extends these observations by demonstrating normal static lung mechanics, normal maximal Pel, and absence of parenchymal disease on high-resolution CT scan. In addition, even if regional parenchymal disease undetectable by CT scan were present, it could not be responsible for reduced TLC and VC, since recoil pressure was normal.

Restrictive dysfunction has been identified in subjects with asthma. ${ }^{2-5,33,34}$ Hudgel et $\mathrm{al}^{2}$ reported reduced TLC and VC with preservation of $\mathrm{FEV}_{1} / \mathrm{VC}$ in a subject with asthma. Abnormalities occurred spontaneously, were elicited in response to exercise, and resolved with bronchodilator treatment. AT and nonuniform distribution of airflow were noted. Subsequently, Miller and Palecki ${ }^{3,33}$ reported reduced TLC with preservation of $\mathrm{FEV}_{1} / \mathrm{VC}$ in patients with asthma. Since distal airways constrict in response to a variety of stimuli, ${ }^{45,46}$ these studies postulated closure/collapse of distal airways and alveolar ducts as the underlying mechanism. Kaminsky and Irvin ${ }^{5}$ obtained pathologic specimens in a patient with reversible restriction due to asthma and demonstrated terminal airway inflammation. In addition, increased VC without change in $\mathrm{FEV}_{1} / \mathrm{NC}$ frequently occurs in patients with asthma following bronchodilator administration ("volume responders"), ${ }^{47-51}$ supporting that reduced lung volume may be a manifestation of airway disease. The present study demonstrates that a similar physiologic pattern may be observed following WTC dust exposure.

Inhalational injury has also been associated with pathologic changes in distal airways (respiratory bronchioles and alveolar ducts), ${ }^{52,53}$ which may not be apparent on chest radiographs. ${ }^{54}$ In addition, distal airway disease presenting as bronchiolitis obliterans was documented following WTC dust exposure..$^{55}$ These patients may demonstrate reduced TLC with preservation of $\mathrm{FEV}_{1} / \mathrm{VC}$ and increased DLCO/VA, similar to observations in the present study.55,56

Insight into the pathologic mechanism for the distal airway dysfunction observed in the present study has recently become available. Lung tissue was analyzed in six WTC dust-exposed subjects with restrictive pattern on pulmonary testing that was unexplained by high-resolution CT scan (including two subjects 
reported in the present study). ${ }^{57}$ Small airway abnormalities were confirmed and included bronchiolitis, small airway fibrosis, and peribronchial lymphoid aggregates. Furthermore, all subjects demonstrated emphysematous changes. These findings provide mechanisms for airway closure due to either intrinsic airway injury (eg, bronchiolitis) and/or loss of structural support of the airway wall (eg, emphysema). The findings may also explain the small magnitude of change and persistent abnormality of IOS parameters noted postbronchodilator.

Although all subjects reported exposure to WTC dust, there are other potential causes for distal airway disease. Obesity was a contributing mechanism, as IOS parameters increased with increasing BMI; however, abnormalities were documented in nonobese subjects. Additionally, $44 \%$ of subjects had a history of smoking or asthma; however, spirometry and IOS parameters did not differ in these vs the remaining subjects. Last, chest wall deformity was unlikely, since physical examination and chest radiographs did not demonstrate abnormalities in any patient. However, of importance is identification of the phenotype that indicates restriction due to airway dysfunction that is applicable to multiple different disease states.

Interpretation of IOS data is confounded by other processes that influence respiratory mechanics. Oscillometric abnormalities may occur in ILD due to interdependence of parenchymal and airway function ${ }^{58}$; however, this was unlikely in our study since parenchymal disease was not evident on high-resolution CT scan. Additionally, IOS abnormalities may occur because of the upper airway shunt effect. ${ }^{22}$ This would be magnified in patients with ILD because of high lung impedance; however, static lung mechanics were normal in this study. In addition, chest wall abnormalities could have influenced IOS measurement of respiratory system impedance, but physical examination and chest radiographs revealed normal chest wall structure. Last, obesity is associated with airway abnormality ${ }^{59,60}$; however, IOS abnormality was noted in nonobese subjects, and no relationship was demonstrable between degree of obesity and TLC. Thus, primary airway dysfunction is more likely in the present study and is supported by bronchodilator responsiveness, nonuniformity of airflow distribution, and CT scan evidence for AT and bronchial wall thickening.

In summary, the phenotype of restrictive dysfunction due to airway disease differs from the phenotype of patients with ILD. Although the current American Thoracic Society/European Respiratory Society guidelines identify low VC as a marker of distal airway disease, reduced TLC was not part of this phenotype. Thus, the patterns of pulmonary dysfunction initially described by Baldwin et $\mathrm{al}^{1}$ should be expanded to differentiate restriction due to inspiratory impairment (eg, parenchymal, pleural, chest wall, and neuromuscular diseases) from restriction due to expiratory impairment (eg, distal airway disease and obesity). Findings on routine testing may allow this distinction. Reduction in $\mathrm{VC}$ due to reduction in ERV with preservation of IC is suggestive of normal static lung mechanics and suggests airway closure. ${ }^{44}$ Reduced VA/TLC indicates nonuniform airflow distribution supporting airway dysfunction. Finally, relative preservation of DLCO is consistent with normal alveolar-capillary interface. This pattern of expiratory restriction due to airway disease was observed following WTC dust exposure, has been previously demonstrated in other clinical settings (eg, asthma), and should be incorporated into the definition of restrictive dysfunction.

\section{ACKNOWLEDGMENTS}

Author contributions: Dr Berger had full access to all of the data in the study and takes responsibility for the integrity of the data and the accuracy of the data analysis.

Dr Berger: contributed to study design, data interpretation, and writing of the manuscript.

Dr Reibman: contributed to referring patients for evaluation, provided clinical and imaging data, and contributed to data interpretation and writing of the manuscript.

Dr Oppenheimer: contributed to study design, data interpretation, and writing of the manuscript.

Dr Vlahos: contributed to review of the chest radiographs and CT scans and writing of the manuscript.

Dr Harrison: contributed patients for study and reviewed the final manuscript submitted for publication.

Dr Goldring: contributed to study design, data interpretation, and writing of the manuscript.

Financial/nonfinancial disclosures: The authors have reported to CHEST that no potential conflicts of interest exist with any companies/organizations whose products or services may be discussed in this article.

Role of sponsors: The Centers for Disease Control and Prevention, National Institutes of Health/National Institute for Occupational Safety and Health, and the American Red Cross played no role in data management or generation of this article.

Other contributions: The work was performed at New York University School of Medicine/Bellevue Hospital, New York, NY.

\section{REFERENCES}

1. Baldwin ED, Cournand A, Richards DW Jr. Pulmonary insufficiency; physiological classification, clinical methods of analysis, standard values in normal subjects. Medicine (Baltimore). 1948;27(3):243-278.

2. Hudgel DW, Cooper D, Souhrada J. Reversible restrictive lung disease stimulating asthma. Ann Intern Med. 1976;85(3): 328-332.

3. Miller A, Palecki A. Restrictive impairment in patients with asthma. Respir Med. 2007;101(2):272-276.

4. Colp C, Williams MH Jr. Total occlusion of airways producing a restrictive pattern of ventilatory impairment. Am Rev Respir Dis. 1973;108(1):118-122.

5. Kaminsky DA, Irvin CG. Anatomic correlates of reversible restrictive lung disease. Chest. 1993;103(3):928-931.

6. Reibman J, Liu M, Cheng Q, et al. Characteristics of a residential and working community with diverse exposure to World 
Trade Center dust, gas, and fumes. J Occup Environ Med. 2009;51(5):534-541.

7. Prezant DJ, Weiden M, Banauch GI, et al. Cough and bronchial responsiveness in firefighters at the World Trade Center site. N Engl J Med. 2002;347(11):806-815.

8. Herbert R, Moline J, Skloot G, et al. The World Trade Center disaster and the health of workers: five-year assessment of a unique medical screening program. Environ Health Perspect. 2006;114(12):1853-1858.

9. Friedman SM, Maslow CB, Reibman J, et al. Case-control study of lung function in World Trade Center Health Registry area residents and workers. Am J Respir Crit Care Med. 2011;184(5):582-589.

10. Reibman J, Lin S, Hwang SA, et al. The World Trade Center residents' respiratory health study: new-onset respiratory symptoms and pulmonary function. Environ Health Perspect. 2005; 113(4):406-411.

11. Mendelson DS, Roggeveen M, Levin SM, Herbert R, de la Hoz RE. Air trapping detected on end-expiratory highresolution computed tomography in symptomatic World Trade Center rescue and recovery workers. J Occup Environ Med. 2007;49(8):840-845.

12. Weiden MD, Ferrier N, Nolan A, et al. Obstructive airways disease with air trapping among firefighters exposed to World Trade Center dust. Chest. 2010;137(3):566-574.

13. Banauch GI, Alleyne D, Sanchez R, et al. Persistent hyperreactivity and reactive airway dysfunction in firefighters at the World Trade Center. Am J Respir Crit Care Med. 2003; 168(1):54-62.

14. Hankinson JL, Odencrantz JR, Fedan KB. Spirometric reference values from a sample of the general U.S. population. Am J Respir Crit Care Med. 1999;159(1):179-187.

15. Oppenheimer BW, Goldring RM, Herberg ME, et al. Distal airway function in symptomatic subjects with normal spirometry following World Trade Center dust exposure. Chest. 2007;132(4):1275-1282.

16. Maslow CB, Friedman SM, Pillai PS, et al. Chronic and acute exposures to the world trade center disaster and lower respiratory symptoms: area residents and workers. Am J Public Health. 2012;102(6):1186-1194.

17. Miller MR, Hankinson J, Brusasco V, et al; ATS/ERS Task Force. Standardisation of spirometry. Eur Respir J. 2005; 26(2):319-338.

18. Wanger J, Clausen JL, Coates A, et al. Standardisation of the measurement of lung volumes. Eur Respir J. 2005;26(3): 511-522.

19. Macintyre N, Crapo RO, Viegi G, et al. Standardisation of the single-breath determination of carbon monoxide uptake in the lung. Eur Respir J. 2005;26(4):720-735.

20. Van Ganse WF, Ferris BG Jr, Cotes JE. Cigarette smoking and pulmonary diffusing capacity. (Transfer factor). Am Rev Respir Dis. 1972;105(1):30-41.

21. Quanjer PH, Tammeling GJ, Cotes JE, Pedersen OF, Peslin R, Yernault JC; Official Statement of the European Respiratory Society. Lung volumes and forced ventilatory flows. Report Working Party Standardization of Lung Function Tests, European Community for Steel and Coal. Eur Respir J Suppl. 1993; 16:5-40.

22. Oostveen E, MacLeod D, Lorino H, et al; ERS Task Force on Respiratory Impedance Measurements. The forced oscillation technique in clinical practice: methodology, recommendations and future developments. Eur Respir J. 2003;22(6): 1026-1041.

23. Miller TK III, Pimmel RL. Standard errors on respiratory mechanical parameters obtained by forced random excitation. IEEE Trans Biomed Eng. 1983;30(12):826-832.
24. Komarow HD, Myles IA, Uzzaman A, Metcalfe DD. Impulse oscillometry in the evaluation of diseases of the airways in children. Ann Allergy Asthma Immunol. 2011;106(3):191-199.

25. Goldman MD, Saadeh C, Ross D. Clinical applications of forced oscillation to assess peripheral airway function. Respir Physiol Neurobiol. 2005;148(1-2):179-194.

26. Kohlhäufl M, Brand P, Scheuch G, Schulz H, Häussinger K, Heyder J. Impulse oscillometry in healthy nonsmokers and asymptomatic smokers: effects of bronchial challenge with methacholine. J Aerosol Med. 2001;14(1):1-12.

27. Niven AS, Backenson TJ, Goldman MD, Hnatiuk OW, Weisman IM. Resistance measured by forced oscillation (IOS) is mouthpiece dependent and reduced in normal subjects using a free flow mouthpiece [abstract]. Am J Respir Crit Care Med. 2003;167:A419.

28. Shiota S, Katoh M, Fujii M, Aoki S, Matsuoka R, Fukuchi Y. Predictive equations and the reliability of the impulse oscillatory system in Japanese adult subjects. Respirology. 2005; 10(3):310-315.

29. de la Hoz RE, Berger KI, Klugh TT, Friedman-Jiménez G, Goldring RM. Frequency dependence of compliance in the evaluation of patients with unexplained respiratory symptoms. Respir Med. 2000;94(3):221-227.

30. Oppenheimer BW, Goldring RM, Berger KI. Distal airway function assessed by oscillometry at varying respiratory rate: comparison with dynamic compliance. COPD. 2009;6(3):162-170.

31. Addrizzo-Harris DJ, Harkin TJ, Tchou-Wong KM, et al. Mechanisms of colchicine effect in the treatment of asbestosis and idiopathic pulmonary fibrosis. Lung. 2002;180(2):61-72.

32. Kanengiser LC, Rapoport DM, Epstein H, Goldring RM. Volume adjustment of mechanics and diffusion in interstitial lung disease. Lack of clinical relevance. Chest. 1989;96(5):1036-1042.

33. Miller A. A simple spirometric clue to asthma: airways obstruction suggested by negative or reduced forced expiratory reserve volume despite normal FEV1-FVC ratio. Mt Sinai J Med. 1990;57(2):85-92.

34. Gilbert R, Auchincloss JH Jr. Reactive airways dysfunction syndrome presenting as a reversible restrictive defect. Lung. 1989;167(1):55-61.

35. Bates JH, Lutchen KR. The interface between measurement and modeling of peripheral lung mechanics. Respir Physiol Neurobiol. 2005;148(1-2):153-164.

36. Fredberg JJ, Mead J. Impedance of intrathoracic airway models during low-frequency periodic flow. J Appl Physiol. 1979; 47(2):347-351.

37. Kjeldgaard JM, Hyde RW, Speers DM, Reichert WW. Frequency dependence of total respiratory resistance in early airway disease. Am Rev Respir Dis. 1976;114(3):501-508.

38. van den Elshout FJ, van Herwaarden CL, Folgering HT. Oscillatory respiratory impedance and lung tissue compliance. Respir Med. 1994;88(5):343-347.

39. Mead J. The lung's "quiet zone". N Engl J Med. 1970;282(23): 1318-1319.

40. Pedley TJ, Schroter RC, Sudlow MF. The prediction of pressure drop and variation of resistance within the human bronchial airways. Respir Physiol. 1970;9(3):387-405.

41. Woolcock AJ, Vincent NJ, Macklem PT. Frequency dependence of compliance as a test for obstruction in the small airways. J Clin Invest. 1969;48(6):1097-1106.

42. Cosio M, Ghezzo H, Hogg JC, et al. The relations between structural changes in small airways and pulmonary-function tests. N Engl J Med. 1978;298(23):1277-1281.

43. Stănescu D. Small airways obstruction syndrome. Chest. 1999; 116(1):231-233

44. Pellegrino R, Viegi G, Brusasco V, et al. Interpretative strategies for lung function tests. Eur Respir J. 2005;26(5):948-968. 
45. Newball HH, Keiser HR. Relative effects of bradykinin and histamine on the respiratory system of man. J Appl Physiol. 1973;35(4):552-556.

46. Nadel JA, Colebatch JH, Olsen CR. Location and mechanism of airway constriction after barium sulfate microembolism. J Appl Physiol. 1964;19:387-394.

47. Woolcock AJ, Read J. Lung volumes in exacerbations of asthma. Am J Med. 1966;41(2):259-273.

48. Ayres SM, Griesbach SJ, Reimold F, Evans RG. Bronchial component in chronic obstructive lung disease. Am J Med. 1974;57(2):183-191.

49. Ramsdell JW, Tisi GM. Determination of bronchodilation in the clinical pulmonary function laboratory. Role of changes in static lung volumes. Chest. 1979;76(6):622-628.

50. Pellegrino R, Rodarte JR, Brusasco V. Assessing the reversibility of airway obstruction. Chest. 1998;114(6):1607-1612.

51. Newton MF, O'Donnell DE, Forkert L. Response of lung volumes to inhaled salbutamol in a large population of patients with severe hyperinflation. Chest. 2002;121(4):1042-1050.

52. Churg A, Wright JL. Small-airway lesions in patients exposed to nonasbestos mineral dusts. Hum Pathol. 1983;14(8):688-693.

53. Guerry-Force ML, Müller NL, Wright JL, et al. A comparison of bronchiolitis obliterans with organizing pneumonia, usual interstitial pneumonia, and small airways disease. Am Rev Respir Dis. 1987;135(3):705-712.
54. Chia KS, Ng TP, Jeyaratnam J. Small airways function of silicaexposed workers. Am J Ind Med. 1992;22(2):155-162.

55. Mann JM, Sha KK, Kline G, Breuer FU, Miller A. World Trade Center dyspnea: bronchiolitis obliterans with functional improvement: a case report. Am J Ind Med. 2005;48(3): 225-229.

56. Kreiss K, Greenberg LM, Kogut SJ, Lezotte DC, Irvin CG, Cherniack RM. Hard-rock mining exposures affect smokers and nonsmokers differently. Results of a community prevalence study. Am Rev Respir Dis. 1989;139(6):1487-1493.

57. Caplan-Shaw CE, Yee H, Rogers L, et al. Lung pathologic findings in a local residential and working community exposed to World Trade Center dust, gas, and fumes. J Occup Environ Med. 2011;53(9):981-991.

58. van Noord JA, Clement J, Cauberghs M, Mertens I, Van de Woestijne KP, Demedts M. Total respiratory resistance and reactance in patients with diffuse interstitial lung disease. Eur Respir J. 1989;2(9):846-852.

59. Oppenheimer B, Berger KI, Segal L, et al. Residual distal airway dysfunction following weight reduction surgery in morbidly obese subjects with normal spirometry [abstract]. Am J Respir Crit Care Med. 2011;183:A3694.

60. Zerah F, Harf A, Perlemuter L, Lorino H, Lorino AM, Atlan G. Effects of obesity on respiratory resistance. Chest. 1993;103(5):1470-1476. 